\title{
Statistical Optimization and Evaluation of a Multi Release Unit Bilayer Tablet of Rizatriptan Benzoate
}

\author{
KAVYA HANDENAHALLI RAMAKRISHNA REDDY AND SAYANI BHATTACHARYYA* \\ Department of Pharmaceutics, Krupanidhi College of Pharmacy, No.12/1 Chikkabellandur, Varthur, Carmelaram Post, \\ Bangalore 560035, India
}

\section{Reddy et al.: Statistical Optimization and Evaluation of Bilayer Tablet of Rizatriptan Benzoate}

\begin{abstract}
Migraine, a neurological condition is often associated with intense, throbbing, crippling headaches for hours to days. Rizatriptan benzoate has established its potential in controlling the symptoms of migraine. The present study aims to formulate a bilayer tablet of rizatriptan with multi release unit matrix embedded in the sustained layer to achieve a pulsatile release of the drug to control the various phases of migraine. A preliminary study on four matrices-F1, F2, F3 and F4 with different proportion of carnauba wax and ethyl cellulose was done to evaluate the release pattern of rizatriptan in fasted state simulated intestinal fluid at pH 6.5. A simplex lattice design was used to find out the optimized ratio of the matrices to control the dissolution of rizatriptan benzoate in a predetermined fashion at different hour's intervals. The release profile was optimized with a blend of three different formulations (F1:F2:F3=0.53:0.24:0.23). Statistical analysis revealed that the percentage error between the predicted and optimum blend was less than $5 \%$. The immediate release layer was formulated with direct compression method using super disintegrants. The evaluation of bilayer tablet was done for hardness, weight variation, friability, uniformity of content and percentage release. The tablet met the criteria of pharmacopoeial requirements. The bilayer tablet of rizatriptan benzoate could able to release the drug instantly as comparable with marketed immediate release tablet of rizatriptan benzoate and could also prolong the release for $24 \mathrm{~h}$. The accelerated stability study also showed the tablets could retain their property at variable temperature and humidity. Therefore, it can be concluded that the bilayer tablet of rizatriptan benzoate embedded in a wax polymer multi release unit matrix has a potential to deliver the drug at a predetermined rate for the effective control of migrainee.
\end{abstract}

Key words: Rizatriptan benzoate, migraine, bilayer tablet, statistical optimization

Migraine is characterized as one of the world's most prevalent and disabling illness, prevalent in the population ranging from children to adults. Rizatriptan benzoate, a selective 5-hydroxytriptamine receptor agonist, is widely used in the management of migraine attacks. It has rapid onset of action and has relatively short plasma half-life. The oral bioavailability is reported to be $47 \%{ }^{[1]}$. It is administered in a dose of 5-10 $\mathrm{mg}$ per oral at the onset of symptoms and is followed by repeated dosing after $2 \mathrm{~h}$ if necessary, with a total daily dose not to exceed $30 \mathrm{mg}^{[2]}$.

Migraine is characterized by four phases namely prodrome, aura, pain phase and postdrome ${ }^{[3]}$. The severity of the pain, duration of the headache, and frequency of attacks vary from person to person. Therefore, prolonging the effect of the drug can be taken as a preventive control so that it can reduce the frequency or severity of migraine attacks.

*Address for correspondence

E-mail: sayanibh@gmail.com

January-February 2021
The current study aims to formulate a bilayer tablet of rizatriptan for proper management of migraine. Bilayer tablet is used for sustaining the plasma drug concentration and is suitable for prolonged release dosage form in which one layer serves as the loading dose and the second layer provides the maintenance dose ${ }^{[4]}$. The design of bilayer tablet dosage form can reduce the dosing frequency, improve patient compliance, and provide less fluctuation of the drug plasma level when compared with conventional therapy. Hence implementation of statistical optimization to fit a suitable controlled release profile is desirable. In

\footnotetext{
This is an open access article distributed under the terms of the Creative Commons Attribution-NonCommercial-ShareAlike 3.0 License, which allows others to remix, tweak, and build upon the work non-commercially, as long as the author is credited and the new creations are licensed under the identical terms
}

Accepted 18 January 2021

Revised 26 September 2020

Received 08 June 2020

Indian J Pharm Sci 2021;83(1):52-59 
the present study, the immediate release layer of the bilayer tablet was formulated using super disintegrants by direct compression method while the sustained release layer was formulated in a multi release unit matrix system of polymer and hydrophobic wax ${ }^{[5,6]}$. Furthermore, rizatriptan benzoate is reported to be a substrate of efflux transporter P-glycoprotein (P-gp), hence, if control can be placed on the release of drug, it can bring better efficacy of the intended therapy. Therefore, the multi release unit of the matrices will prevent the overshoot of drug release at the absorption window. This approach can be beneficial for improving the oral bioavailability, economic utilization of the drug and can provide an affordable therapy.

The review of the literatures revealed the study of sustained effect of rizatriptan from a transdermal patch and a matrix tablet, hence a bilayer tablet with a multi release unit matrix can be a novel and promising mode of immediate and pulsatile release of rizatriptan in the treatment of migraine for longer duration ${ }^{[7,8]}$.

\section{MATERIALS AND METHODS}

Rizatriptan benzoate was gifted from Azakem Laboratories Pvt. Ltd, Hyderabad, India. Ethyl cellulose was a gift sample from Loba Chemie Pvt. Ltd, Mumbai, India. Microcrysralline cellulose-102, Avicel was purchased from Kemphasol, Mumbai, India. The other reagents and chemicals were of analytical grade.

\section{Drug excipient compatibility studies:}

The incompatibility between drug and other excipients was assessed by Fourier Transmission Infrared spectrophotometer (FT-IR) (8600, Shimadzu Corporation, Japan) using potassium bromide (KBr) pellet method. The pure drug, a physical mixture of pure drug with carnauba wax and ethyl cellulose and a blank formulation were scanned over a range of 400 $-4000 \mathrm{~cm}^{-1}$. The spectra were analyzed for drug excipients interactions by comparing with the preservation of functional groups of the pure drug ${ }^{[9]}$.

\section{Preparation of sustained release matrix of rizatriptan benzoate with wax and polymer:}

The required amount of drug and ethyl cellulose was dispersed in minimum quantity of ethanol with continuous stirring. The carnauba wax was melted at a temperature above $82^{\circ}$. The drug polymer dispersion was added to the molten wax to form a polymer wax matrix of the drug ${ }^{[10]}$. The drug: wax: polymer ratio was
TABLE 1: COMPOSITION OF SUSTAINED RELEASE MATRIX

\begin{tabular}{lcccc}
\hline Batch no. & F1 & F2 & F3 & F4 \\
\hline Drug (mg) & 100 & 100 & 100 & 100 \\
Carnauba wax (mg) & 100 & 100 & 100 & 100 \\
Ethyl cellulose (mg) & 20 & 15 & 10 & 5 \\
\hline
\end{tabular}

varied and four such matrices were prepared (Table 1). The rest amount of alcohol was evaporated by heating the formulation on hot plate. The drug polymer matrix was air dried, triturated and was passed through 1000 $\mu \mathrm{m}$ sieve for uniform size distribution of the particles ${ }^{[1]}$.

\section{Determination of drug content of sustained release matrix:}

The prepared sustained release matrix was assessed for drug content by dissolving in a common solvent ${ }^{[12]}$. A known quantity of matrix was crushed in a mortar, and then was dissolved in methanol by centrifugation at $3000 \mathrm{rpm}$ for $30 \mathrm{~min}$. An aliquot $0.1 \mathrm{ml}$ was withdrawn, filtered using nylon syringe filter $(0.45 \mu \mathrm{m}, 25 \mathrm{~mm})$, diluted suitably with fasted state simulated intestinal fluid (FaSSIF) solution and was analyzed Ultraviolet (UV) spectrophotometrically (Shimadzu UV-1800) against blank solution of FaSSIF at $280 \mathrm{~nm}^{[13]}$.

\section{Drug release studies:}

The sustained release matrix equivalent to $50 \mathrm{mg}$ of drug from different batches was subjected to in vitro release studies as per Indian Pharmacopoeia (IP) protocol ${ }^{[14]}$. As the absorption of drug is affected by intake of food and the drug is administered in empty stomach, hence FaSSIF was used as dissolution media for testing the release of drug ${ }^{[15,16]}$.

The release study of all the four rizatriptan benzoate sustained release matrices was determined using dissolution testing apparatus United States Pharmacopeia (USP) type II (Paddle type) (Electro lab). The dissolution testing was performed using $900 \mathrm{ml}$ of FaSSIF (pH 6.5) solution, temperature was maintained at $37 \pm 1^{\circ}$ with a rotational speed at $50 \mathrm{rpm}$. An aliquot of $1 \mathrm{ml}$ was withdrawn at a specific time interval for $8 \mathrm{~h}$ and same volume was replaced each time with equal quantity of fresh dissolution medium maintained at same temperature. Each aliquot was filtered through nylon syringe filter $(0.45 \mu \mathrm{m}, 25 \mathrm{~mm})$. The filtered sample was diluted suitably with FaSSIF (pH 6.5) and absorbance was measured at $280 \mathrm{~nm}$ spectrophotometrically. All trials were carried out in triplicates. 
Statistical optimization of sustained release Compression of bilayer tablet: matrices:

Higher the amount of polymer and wax in the matrix, lower was the drug release from the matrix. This property was utilized by blending three different sustained release matrices of the formulations F1, F2 and F3 in a suitable ratio, to achieve a target release at $2^{\text {nd }}, 4^{\text {th }}$, $6^{\text {th }}$ and $8^{\text {th }}$ h. A simplex lattice design was used using John's Macintosh Project (JMP) V13 software, and 21 experimental runs were carried out by mixing different weight proportions of all the three formulations ${ }^{[17,18]}$.

The maintenance dose $(\mathrm{Dm})$ was calculated based on steady state plasma concentration $\left(\mathrm{Cp}_{\mathrm{ss}}\right)$, dosing interval $(\tau)$ and total clearance $\left(\mathrm{CL}_{\mathrm{T}}\right)$ of the drug by the following formula. $\mathrm{Dm}=\mathrm{Cp}_{\mathrm{ss}} \times \tau \times \mathrm{CL}_{\mathrm{T}}$. The literature reported the $\mathrm{Cp}_{\mathrm{ss}}=0.139 \mu \mathrm{g} / \mathrm{ml}, \tau=2 \mathrm{~h}$, and $\mathrm{CL}_{\mathrm{T}}$ $=32.34 \mathrm{ml} / \mathrm{min}^{[19]}$.

The optimization of the simplex lattice design was aimed to achieve a target release of approximately $20 \%, 35-40 \%, 50-60 \%$ and $70-80 \%$ at; $2^{\text {nd }}, 4^{\text {th }}, 6^{\text {th }}$ and $8^{\text {th }} \mathrm{h}$ respectively ${ }^{[20]}$.

\section{Preparation of optimized sustained release matrix:}

The optimized blend (Fopt) blend and the other tableting ingredients (Table 2) were passed through \# 40 and mixed well in double cone blender. Lubrication was done with magnesium stearate. The powder blend was subjected to compression with suitable tablet tooling and the tablet weight was adjusted to $150 \mathrm{mg}$.

\section{Preparation of immediate release layer:}

The weight of the immediate layer was adjusted to $75 \mathrm{mg}$. Drug and the other ingredients were passed through \# 40 and then mixed in a double cone blender (Table 2), followed by addition of lubricant and compression with suitable tablet tooling ${ }^{[21]}$.

TABLE 2: COMPOSITION OF SUSTAINED RELEASE LAYER

\begin{tabular}{lcc}
\hline Ingredients & $\begin{array}{c}\text { Sustained } \\
\text { release layer }\end{array}$ & $\begin{array}{c}\text { Immediate } \\
\text { release layer }\end{array}$ \\
\hline $\begin{array}{l}\text { Rizatriptan Benzoate }(\mathrm{mg}) \\
\text { Blend of SR matrix of }\end{array}$ & - & 5 \\
Rizatriptan benzoate & 10 & - \\
(mg eqv) & & \\
Microcrystalline cellulose & 133 & 63 \\
(mg) & 5 & 5 \\
Sodium starch glycolate $(\mathrm{mg})$ & 1 & 1 \\
Aerosil (mg) & 1 & 1 \\
Magnesium stearate $(\mathrm{mg})$ &
\end{tabular}

Direct compression method was employed to prepare the bilayer tablets of rizatriptan benzoate. The sustained release layer was compressed into the die cavity of punching machine using $9 \mathrm{~mm}$ circular punches with a mild compression force $\left(2-3 \mathrm{~kg} / \mathrm{cm}^{3}\right)^{[22]}$. Then the immediate release powder was fed manually into the die cavity and compressed using $9 \mathrm{~mm}$ circular punches to obtain hardness between $5-7 \mathrm{~kg} \mathrm{~cm}^{-2}$. The entire process was carried out by using 10 stations, Rimek rotary mini tablet press, Karnavati engineering ltd.

\section{Evaluation of bilayer tablets:}

Determination of hardness: To determine the resistance of the tablet to breakage during storage, transportation and handling, hardness test was carried out in Monsanto hardness tester. Five tablets were selected at random and the hardness of each tablet was measured in terms of $\mathrm{kg} / \mathrm{cm}^{2[23]}$. Measurements were carried in triplicates.

Determination of friability: The friability test was carried out in Roche friabilator, by rotating the drum at $25 \mathrm{rpm}$. Pre weighed 30 tablets were placed in the rotating drum. The tablets were weighed again. The friability was expressed in percentage ${ }^{[24]}$. The experimentation was carried out thrice to minimize the error. The percentage friability was calculated.

Weight variation test:The IP (2018) method was used to find out the uniformity of weight of the bilayer tablets $^{[25]}$. 20 tablets were selected randomly, and the average weight was determined. The individual weight of each tablet was compared with the average weight. The percentage deviation in weight was calculated.

Uniformity of content: 10 tablets were selected randomly, ground in a mortar to get fine powder. An amount equivalent to $50 \mathrm{mg}$ drug was extracted with $100 \mathrm{ml}$ of 0.1 Normal $(\mathrm{N})$ hydrochloric acid, followed by filtration through Whatman filter paper and then diluted suitably with FaSSIF solution. The percentage drug content was determined by analyzing the sample spectrophotometrically at $280 \mathrm{~nm}$. Three trials were made to minimize the detection error.

In vitro drug release study of rizatriptan benzoate bilayer tablets: The release rate of rizatriptan benzoate bilayer tablets was determined by using dissolution 
testing apparatus USP type II (Paddle type) at 50 $\mathrm{rpm}$. The dissolution was performed using $900 \mathrm{ml}$ of FaSSIF of $\mathrm{pH} 6.5$ at $37 \pm 0.5^{\circ}$ temperature. During the study $1 \mathrm{ml}$ aliquot was withdrawn at a specified time interval for $24 \mathrm{~h}$. The sample was filtered through nylon syringe filter $(0.45 \mu \mathrm{m}, 25 \mathrm{~mm})$ and the dissolution media was replaced by an equal amount of FaSSIF maintained at same temperature ${ }^{[22,26]}$. An aliquot of 1 $\mathrm{ml}$ was diluted subsequently with $10 \mathrm{ml} \mathrm{FaSSIF}$ and analyzed spectrophotometrically at $280 \mathrm{~nm}$. All trials were carried out in triplicates.

Stability study: Accelerated stability study for $3 \mathrm{mo}$ was carried out for the tablets at $30^{\circ} / 75 \%$ relative humidity (RH), and $40^{\circ} / 75 \%$. During the study, the tablets were stored in screw capped glass bottles. They were evaluated for various parameters like hardness, weight variation, and dissolution. The tablets were evaluated at a periodic interval of 30,60 and $90 \mathrm{~d}^{[27,28]}$. Three trials were made for each observation.

\section{RESULTS AND DISCUSSION}

The FT-IR spectrum of rizatriptan benzoate (fig. 1), revealed the presence of major peaks at $1197 \mathrm{~cm}^{-1}, 1567 \mathrm{~cm}^{-1}, 1606 \mathrm{~cm}^{-1}, 1735 \mathrm{~cm}^{-1}, 3055 \mathrm{~cm}^{-1}$, $3122 \mathrm{~cm}^{-1}$ and $3450 \mathrm{~cm}^{-1}$, corresponding to the presence of tertiary amine, triazole $\mathrm{N}=\mathrm{N}$ stretch, $\mathrm{C}=\mathrm{N}$ stretch, benzoate group, indole group, aliphatic chain and $\mathrm{N}-\mathrm{H}$ stretch respectively. Major frequencies related to the functional groups of pure drug remained intact in the physical mixture of wax and ethyl cellulose. There was neither addition nor deletion of any major peaks, hence the study concluded the compatibility of the drug with carnauba wax and ethyl cellulose.

Different polymer wax matrices of rizatriptan benzoate were formulated to determine the effect of composition of sustained release matrix on drug release. The formulations were subjected to various evaluation studies. All the formulations showed good yield. The drug content uniformity revealed that all the formulations had a drug loading of $98 \%$ approximately and could release the drug slowly upto $8 \mathrm{~h}$ (Table 3 ).

The in vitro release study for $8 \mathrm{~h}$ revealed that the composition of the sustained layer matrix had immense effect on drug release. The release rate was inversely proportional to the amount of ethyl cellulose in the matrix. Linear regression analysis of the release data was done to investigate the release kinetics of best fit. The best fit for release kinetics of different models was found out from the correlation coefficient (Table 4).

The release rate constants for different models were also calculated. The regression coefficient for all formulations from the matrices followed Higuchi kinetics. This could be explained by the formation of a monolithic system of wax and polymer and from which the release of drug followed a diffusion controlled release as per Higuchi model. The fig. 2 explained the release of rizatriptan benzoate from all the formulations increased linearly with square root of time following Higuchi model. Analysis of the data by Ritger Peppas model showed that " $n$ " values of all the formulations were within $0.44<\mathrm{n}<1$, indicating formation of non swellable matrix with anomalous release as indicated in Table 5 and fig. 3. This is an indication of drug release

\section{TABLE 3: IN VITRO DISSOLUTION STUDIES OF SUSTAINED RELEASE MATRIX}

\begin{tabular}{lccc}
\hline $\begin{array}{l}\text { Formulation } \\
\text { code }\end{array}$ & $\begin{array}{c}\text { Percentage } \\
\text { yield }\end{array}$ & $\begin{array}{c}\text { Percentage } \\
\text { drug content }^{*}\end{array}$ & $\begin{array}{c}\text { Percentage CDR } \\
\text { at } 8 \mathrm{~h}^{*}\end{array}$ \\
\hline F1 & 68.18 & $98 \pm 0.30$ & $60.76 \pm 0.96$ \\
F2 & 93.02 & $98.40 \pm 0.61$ & $68.79 \pm 0.70$ \\
F3 & 95.24 & $98.30 \pm 0.81$ & $71.50 \pm 0.50$ \\
F4 & 92.68 & $97.75 \pm 0.87$ & $79.61 \pm 0.29$ \\
\hline
\end{tabular}

Each value represents as mean \pm Standard deviation (SD)

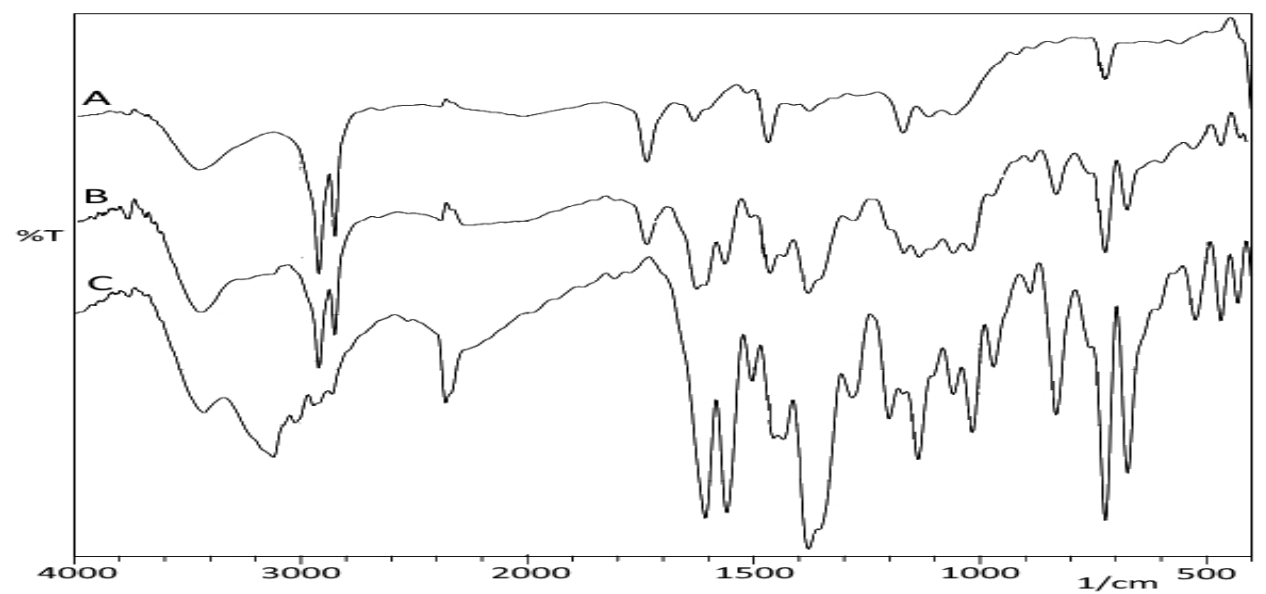

Fig. 1: FTIR spectra of blank formulation (A), drug with excipients (B), pure drug (C) 
www.ijpsonline.com

TABLE 4: CORRELATION COEFFICIENTS OF SUSTAINED RELEASE MATRIX

\begin{tabular}{|c|c|c|c|c|c|c|c|c|c|}
\hline \multirow{2}{*}{$\begin{array}{l}\text { Formulation } \\
\text { code }\end{array}$} & \multicolumn{8}{|c|}{ Correlation coefficients and rate constants } & \multirow{2}{*}{ Best fit model } \\
\hline & $\mathbf{R}^{0}$ & $\mathbf{K}^{0}$ & $\mathbf{R}^{1}$ & $\mathbf{K}^{1}$ & $\mathbf{R}^{\mathrm{HG}}$ & $\mathrm{K}^{\mathrm{HG}}$ & $\mathbf{R}^{\mathrm{HC}}$ & $\mathrm{K}^{\mathrm{HC}}$ & \\
\hline$\overline{\mathrm{F} 1}$ & 0.981 & 0.152 & 0.989 & 0.001 & 0.988 & 3.11 & 0.804 & 0.01 & Higuchi \\
\hline $\mathrm{F} 2$ & 0.97 & 0.178 & 0.994 & 0.001 & 0.997 & 3.72 & 0.782 & 0.01 & Higuchi \\
\hline F3 & 0.965 & 0.173 & 0.991 & 0.001 & 0.995 & 3.63 & 0.743 & 0.01 & Higuchi \\
\hline F4 & 0.943 & 0.182 & 0.98 & 0.001 & 0.991 & 3.89 & 0.714 & 0.01 & Higuchi \\
\hline
\end{tabular}

$\mathrm{R}^{0}$-Correlation coefficient for zero order $\mathrm{R}^{1}$-Correlation coefficient for first order, $\mathrm{R}^{\mathrm{HG}}$-Correlation coefficient for Higuchi $\mathrm{R}^{\mathrm{HC}}$-Correlation coefficient for Hixoncrowell, $\mathrm{K}^{0}$-Release rate constant for zero order $\mathrm{K}^{1}$-Release rate constant for first order, $\mathrm{K}^{\mathrm{HG}}$-Release rate constant for Higuchi $\mathrm{K}^{\mathrm{HC}}$-Release rate constant for Hixoncrowell

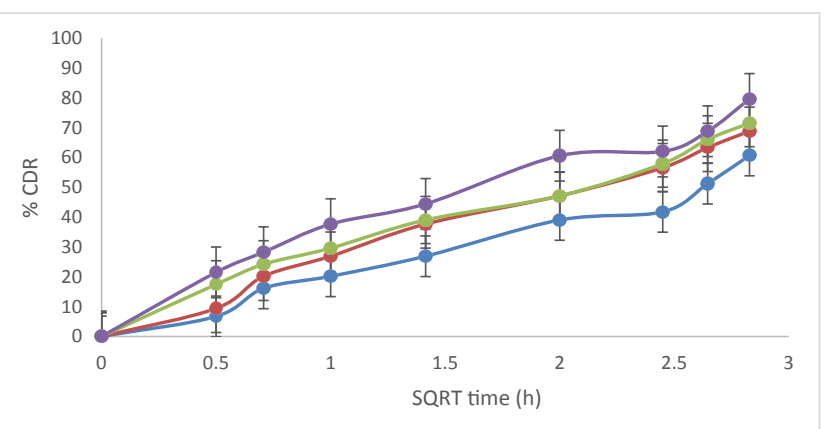

Fig. 2: Higuchi plot for sustained release matrix of all formulations

by Higuchi kinetics through erosion of the wax and polymer matrix ${ }^{[23]}$.

Statistical optimization of predetermined drug release from the blend of different wax polymer matrix of rizatriptan benzoate was carried out using design of experiments. A preliminary study with a combination of $\mathrm{F} 1: \mathrm{F} 2: \mathrm{F} 3: \mathrm{F} 4=1: 1: 1: 1$ could not achieve a desired sustained release of drug. F4 was avoided in the selection as the release of drug from F4 was comparatively high over a period. Hence the formulations F1, F2 and F3 were selected based on their very slow, slow and medium release of drug to create the multi release unit system. Therefore, a simplex lattice mixture design was adopted to optimize the drug release with formulation F1, F2 and F3. The weight fraction of three different matrices (F1, F2 and F3) in a blend was taken as independent variables and was estimated statistically for the percent cumulative drug release (CDR or CR) at $2^{\text {nd }}, 4^{\text {th }}, 6^{\text {th }}$ and $8^{\text {th }} \mathrm{h}$ to attend a preset release of drug (Table 6). The polynomial models for each response were generated and validated through analysis of variance (ANOVA) (Table 7). A complex nonlinear relationship between the independent and the response variables was obtained (Table 8).

The design yielded a numerical optimization of the model at $\mathrm{CR} 2=20 \%$, CR $4=35 \%$, CR $6=51 \%$, and $\mathrm{CR} 8=76 \%$. The predicted blend of matrices was obtained as F1/ $F 2 / F 3=0.53: 0.24: 0.23$ with high desirability statistics
TABLE 5: RITGER PEPPAS MODEL CONSTANTS

\begin{tabular}{lcc}
\hline Formulation code & $\mathbf{N}$ & $\mathrm{K}$ \\
\hline F1 & 0.648 & 1.276 \\
F2 & 0.539 & 2.91 \\
F3 & 0.435 & 5.22 \\
F4 & 0.3936 & 7.32 \\
\hline
\end{tabular}

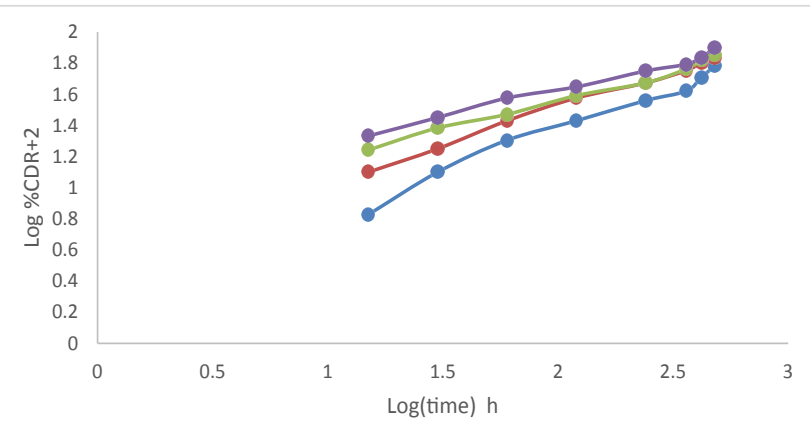

Fig. 3: Ritger Peppas plot

of 0.7. By blending the sustained release matrices of the formulations in the above ratio, dissolution study was carried out for the optimized blend. The release of predicted optimum blend was compared with the experimental blend. It was found that the release from experimental blend was almost similar with target release as predicted ${ }^{[29]}$. The predicted and optimized release parameters are listed in Table 9.

The immediate layer tablet of rizatriptan benzoate showed a drug content of $97.5 \pm 0.41 \%$ and percentage release at $30 \mathrm{~min}$ of $90.7 \pm 1.22$.

Tablet properties such as hardness, weight variation, friability, and drug content were evaluated. The bilayer tablets met the limits of the entire test as per Indian Pharmacopoeial limits (Table 10).

The dissolution study revealed that the bilayer tablet of rizatriptan benzoate (equivalent to $15 \mathrm{mg}$ ) was able to release more than $35.51 \%$ amounting to $5.25 \mathrm{mg}$ of total drug release in $900 \mathrm{ml}$ of dissolution media in first $30 \mathrm{~min}$. The release was compared with the marketed tablet of $5 \mathrm{mg}$ strength which corresponds to 
TABLE 6: SIMPLEX LATTICE DESIGN FOR RIZATRIPTAN BENZOATE SUSTAINED RELEASE MATRIX BLEND

\begin{tabular}{lccccccc}
\hline $\begin{array}{l}\text { Blended } \\
\text { Formulation }\end{array}$ & $\begin{array}{c}\text { Sustained release matrices of rizatriptan } \\
\text { benzoate }\end{array}$ & \multicolumn{5}{l}{ Responses modelled* } \\
\hline B1 & F1 & F2 & F3 & CR2 & CR4 & CR6 & CR8 \\
B2 & 0 & 1 & 0 & 21.4 & 40.1 & 52.6 & 81.1 \\
B3 & 0.4 & 0.6 & 0 & 20 & 32.5 & 46.5 & 73.5 \\
B4 & 0 & 0 & 1 & 22.1 & 38.8 & 54.1 & 79.7 \\
B5 & 0.8 & 0 & 0.2 & 24.2 & 49.9 & 54.8 & 85.27 \\
B6 & 0.2 & 0 & 0.8 & 26.3 & 40.8 & 57 & 89.4 \\
B7 & 0 & 0.2 & 0.8 & 17.3 & 31 & 65.2 & 70 \\
B8 & 0 & 0.8 & 0.2 & 25.6 & 45 & 63 & 87.3 \\
B9 & 0.2 & 0.6 & 0.2 & 16.6 & 28.4 & 49.9 & 64.49 \\
B10 & 0.6 & 0 & 0.4 & 27.6 & 43.6 & 65 & 88.06 \\
B11 & 0.2 & 0.8 & 0 & 17.3 & 30.4 & 51.3 & 67.27 \\
B12 & 0.4 & 0.2 & 0.4 & 20.1 & 35.3 & 53.4 & 77.66 \\
B13 & 0.2 & 0.2 & 0.6 & 22.1 & 41.5 & 56.8 & 82.51 \\
B14 & 0.6 & 0.4 & 0 & 18.7 & 31.1 & 43.0 & 72.1 \\
B15 & 0.4 & 0 & 0.6 & 28 & 49 & 71 & 92.2 \\
B16 & 1 & 0 & 0 & 22.8 & 43.6 & 60.6 & 84.6 \\
B17 & 0 & 0.6 & 0.4 & 20.7 & 33.9 & 45.1 & 75.5 \\
B18 & 0.8 & 0.2 & 0 & 27 & 55.4 & 70 & 96.37 \\
B19 & 0.4 & 0.4 & 0.2 & 18 & 33.2 & 46 & 69.35 \\
B20 & 0.2 & 0.4 & 0.4 & 27.6 & 47.1 & 70 & 90.1 \\
B21 & 0.6 & 0.2 & 0.2 & 28.9 & 50.5 & 72 & 94.31 \\
\hline CRx & 0 & 0.4 & 0.6 & 26.3 & 44.3 & 68.2 & 86 \\
\hline
\end{tabular}

$\mathrm{CRx}=$ Percentage cumulative drug release at $\mathrm{x}^{\text {th }} \mathrm{h}$

TABLE 7: ANOVA TABLE FOR DIFFERENT RESPONSES

\begin{tabular}{lcccccc}
\hline Response variable & Dosage Form & Sum of squares & Mean square & F Ratio & Probability $>F$ & $R^{2}$ actual vs. predicted \\
\hline CR2 & 5 & 294.03952 & 58.8079 & 29.9038 & $<0.0001$ & 0.91 \\
CR4 & 5 & 1017.8307 & 203.566 & 16.9562 & $<0.0001$ & 0.85 \\
CR6 & 5 & 1185.1738 & 237.035 & 6.3430 & $<0.002$ & 0.80 \\
CR8 & 5 & 1672.5150 & 334.503 & 80.3073 & $<0.0001$ & 0.96 \\
\hline
\end{tabular}

TABLE 8: NON LINEAR RELATIONSHIP BETWEEN INDEPENDENT AND DEPENDENT VARIABLES

\begin{tabular}{lc}
\hline Response variable & Model equations \\
\hline CR2 & $16.06 \times \mathrm{F} 1+23.73 \times \mathrm{F} 2+28.6 \times \mathrm{F} 3+\mathrm{F} 1 \times(\mathrm{F} 2 \times-6.10)+\mathrm{F} 1 \times(\mathrm{F} 3 \times 1.22)+\mathrm{F} 2 \times(\mathrm{F} 3 \times 4.28)$ \\
$\mathrm{CR} 4$ & $27.9 \times \mathrm{F} 1+43.19 \times \mathrm{F} 2+54.62 \times \mathrm{F} 3+\mathrm{F} 1 \times(\mathrm{F} 2 \times-10.19)+\mathrm{F} 1 \times(\mathrm{F} 3 \times-5.14)+\mathrm{F} 2 \times(\mathrm{F} 3 \times-9.77)$ \\
$\mathrm{CR} 6$ & $50.41 \times \mathrm{F} 1+60.63 \times \mathrm{F} 2+75.46 \times \mathrm{F} 3+\mathrm{F} 1 \times(\mathrm{F} 2 \times-16.29)+\mathrm{F} 1 \times(\mathrm{F} 3 \times-42.39)+\mathrm{F} 2 \times(\mathrm{F} 3 \times-5.65)$ \\
$\mathrm{CR} 8$ & $63.07 \times \mathrm{F} 1+84.09 \times \mathrm{F} 2+97.36 \times \mathrm{F} 3+\mathrm{F} 1 \times(\mathrm{F} 2 \times-3.20)+\mathrm{F} 1 \times(\mathrm{F} 3 \times 2.36)+\mathrm{F} 2 \times(\mathrm{F} 3 \times-2.70)$ \\
\hline
\end{tabular}

TABLE 9: PREDICTED AND OPTIMIZED RELEASE PARAMETER

\begin{tabular}{lcccc}
\hline & CR2 & CR4 & CR6 & CR8 \\
\hline Predicted & 20.43 & 35.31 & 50.94 & 75.7 \\
Experimented $^{*}$ & $20.15 \pm 0.35$ & $34.95 \pm 0.53$ & $49.76 \pm 0.04$ & $74.07 \pm 0.55$ \\
Percentage Bias & 1.37 & 1.01 & 2.31 & 2.15 \\
\hline
\end{tabular}

Each value represents as mean \pm SD

TABLE 10: EVALUATION OF BILAYER TABLET OF RIZATRIPTAN BENZOATE

\begin{tabular}{lcccccc}
\hline & Weight $(\mathrm{mg})^{*}$ & $\begin{array}{c}\text { Hardness }(\mathrm{kg} / \\
\left.\mathrm{cm}^{2}\right)^{*}\end{array}$ & $\begin{array}{c}\text { Friability } \\
(\text { percentage)* }\end{array}$ & $\begin{array}{c}\text { Thickness } \\
(\mathrm{mm})^{*}\end{array}$ & $\begin{array}{c}\text { Drug content } \\
\text { (percentage)* }^{*}\end{array}$ & $\begin{array}{c}\text { Disintegration } \\
\text { time }(\mathrm{min})^{*}\end{array}$ \\
\hline $\begin{array}{l}\text { Post compression } \\
\text { studies }\end{array}$ & $225 \pm 12$ & $5.2 \pm 1.2$ & $0.5 \pm 0.3$ & $2.9 \pm 0.1$ & $98.5 \pm 1.5$ & $3 \pm 2$ \\
\hline
\end{tabular}

Each value represents as mean \pm SD 
TABLE 11: STABILITY STUDY OF BILAYER TABLETS

\begin{tabular}{|c|c|c|c|c|c|c|c|c|}
\hline $\begin{array}{l}\text { Testing } \\
\text { conditions }\end{array}$ & \multicolumn{4}{|c|}{$30 \% / 75 \% \mathrm{RH}$} & \multicolumn{4}{|c|}{$40^{\circ} / 75 \% \mathrm{RH}$} \\
\hline $\begin{array}{l}\text { Period of } \\
\text { evaluation }\end{array}$ & Appearance & $\begin{array}{c}\text { Hardness } \\
\left(\mathrm{kg} / \mathrm{cm}^{2}\right)\end{array}$ & $\begin{array}{c}\text { Weight } \\
\text { variation }(\mathrm{mg})\end{array}$ & $\begin{array}{l}\text { Percentage } \\
\text { drug release }\end{array}$ & Appearance & $\begin{array}{l}\text { Hardness } \\
\left(\mathrm{kg} / \mathrm{cm}^{2}\right)\end{array}$ & $\begin{array}{c}\text { Weight } \\
\text { variation }(\mathrm{mg})\end{array}$ & $\begin{array}{l}\text { Percentage } \\
\text { drug release }\end{array}$ \\
\hline $30 \mathrm{~d}$ & $\begin{array}{l}\text { Off white } \\
\text { color }\end{array}$ & $5.2 \pm 1.89$ & $225 \pm 6.01$ & $69.93 \pm 0.31$ & $\begin{array}{l}\text { Off white } \\
\text { color }\end{array}$ & $5.13 \pm 1.10$ & $225 \pm 5.61$ & $70 \pm 0.15$ \\
\hline $60 \mathrm{~d}$ & $\begin{array}{l}\text { Off white } \\
\text { color }\end{array}$ & $5.15 \pm 1.16$ & $224.86 \pm 5.68$ & $69.87 \pm 0.23$ & $\begin{array}{l}\text { Off white } \\
\text { color }\end{array}$ & $5.1 \pm 1.05$ & $225.1 \pm 1.22$ & $70.2 \pm 0.89$ \\
\hline $90 \mathrm{~d}$ & $\begin{array}{l}\text { Off white } \\
\text { color }\end{array}$ & $5.0 \pm 0.96$ & $224.75 \pm 2.6$ & $69.77 \pm 0.14$ & $\begin{array}{l}\text { Off white } \\
\text { color }\end{array}$ & $5.0 \pm 1.12$ & $225.1 \pm 3.1$ & $70.51 \pm 0.60$ \\
\hline
\end{tabular}

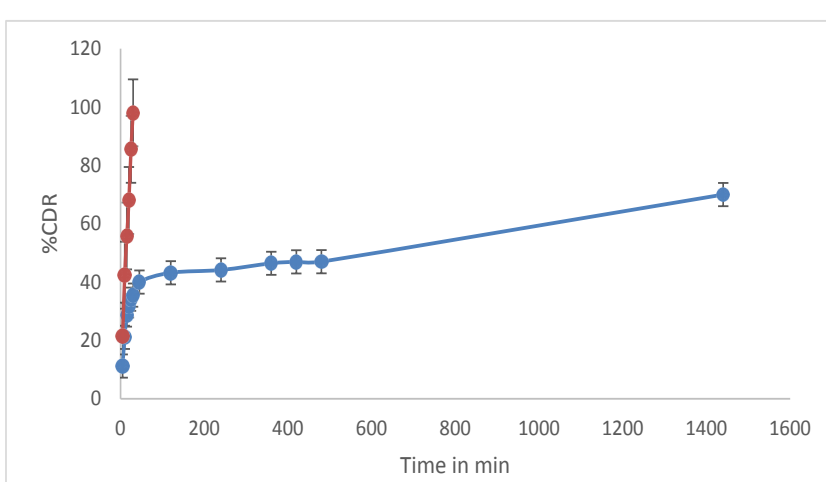

Fig. 4: Comparative dissolution studies of rizatriptan benzoate bilayer tablet with marketed formulation

$95 \%$ release and equivalent to $4.9 \mathrm{mg}$ drug release in $900 \mathrm{ml}$ of same dissolution media within $30 \mathrm{~min}$. The comparative dissolution graph is shown in fig. 4. Hence, the in vitro drug release study of the bilayer tablet of rizatriptan benzoate provided almost an equivalent drug release within $30 \mathrm{~min}$ as that of the marketed product and could prolong the release. A $24 \mathrm{~h}$ study revealed that the bilayer tablet was able to release up to $70 \%$ of the total dose. Therefore, the formulated bilayer tablet could provide an immediate and prolonged release of rizatriptan benzoate, can provide a day long therapy in effective management of migraine.

The short term stability study of the formulations for 3 mo revealed that there was no significant change in the physical appearance, hardness, weight and dissolution of the tablets (Table 11). In conclusion the study was undertaken to achieve a predetermined release of rizatriptan benzoate in the treatment of migraine over an extended period to maximize the therapeutic benefits and economic utilization of drug and to enhance patient's compliance. A bilayer tablet of rizatriptan benzoate was successfully formulated using sodium starch glycolate as immediate release and carnauba wax and ethyl cellulose for the sustained release matrix. A simplex lattice design was used to convert the sustained release layer into a multi release unit matrix to achieve a pulsatile release for longer duration. The design was successful in predicting an optimized blend to match a predetermined target release profile. The bilayer tablet of rizatriptan benzoate was able to release comparable amount of drug in the initial 30 min with the marketed formulation and could sustain the release up to $70 \%$ of the total dose in $24 \mathrm{~h}$. The results of the present study clearly indicated that the bilayer tablets were stable and could be a promising extended delivery of rizatriptan benzoate in the treatment of migraine.

\section{Acknowledgements:}

The authors are grateful to Azakem Laboratories Pvt. Ltd, Hyderabad, India for their generous support of providing the drug rizatriptan benzoate. They are highly respectful to the management and principal of Krupanidhi college of Pharmacy for providing required infrastructure to carry out the work.

\section{Conflict of Interests:}

The authors declared no conflict of interest.

\section{REFERENCES}

1. Chen J, Jiang WM, Xie YL, Jin L, Mei N, Jiang XG. Evaluation of the bioequivalence and pharmacokinetics of two formulations of rizatriptan after single oral administration in healthy volunteers. Arzneimittelforschung 2005;55(7):355-8.

2. Maxalt description. Rxlist; 2020.

3. Villalon CM, Centurion D, Valdivia LF, De Vries P, Saxena PR. An introduction to migraine: from ancient treatment to functional pharmacology and antimigraine therapy. Proc West Pharmacol Soc 2002;45;199-210.

4. Roy SK, Naskar SW, Kundu SU, Koutsu KE. Formulation and evaluation of sustained release bilayer tablets of propranolol hydrochloride. Int J Pharm Pharm Sci 2015;7:264-9.

5. Chaudhary SA, Mehta TA, Chaudhary AB. Formulation, development and evaluation of fast disintegrating tablets of rizatriptan benzoate using novel adjuvants. Int $\mathrm{J}$ Chem Tech Res 2010;2(2):1026-30.

6. Huang HP, Mehta SC, Radebaugh GW, Fawzi MB. Mechanism of drug release from an acrylic polymer-wax matrix tablet. J Pharm Sci 1994;83(6):795-7.

7. Ajina CT, Charyulu NR, Sandeep DS. Rizatriptan transdermal patches for the treatment of migraine. Res J Pharm Technol 
2018;11(3):873-8.

8. Jose J, Jayapraksah V, Nayak P. Formulation and evaluation of rizatriptan matrix tablet. Res J Pharm Technol 2016;9(2):11520 .

9. Hiremath D, Goudanavar P, Patil SS, Chowgule PY, Reddy SR, Sirse KK. Design and In vitro evaluation of rapidly disintegrating tablets of rizatriptan benzoate. Res J Pharm Technol 2011;4(8):1227-33.

10. Bhalekar MR, Madgulkar AR, Sheladiya DD, Kshirsagar SJ, Wable ND, Desale SS. Statistical optimization of sustained release venlafaxine HCI wax matrix tablet. Indian J Pharm Sci 2008;70(4):472-6.

11. Nart V, Beringhs AO, Franca MT, de Espindola B, Pezzini BR, Stulzer HK. Carnauba wax as a promising excipient in melt granulation targeting the preparation of mini-tablets for sustained release of highly soluble drugs. Mater Sci Eng C 2017;70(1):250-7.

12. Ramya DD, Fathima A, Vedha BN. Efavirenz-ethyl cellulose microparticles for sustained release anti-HIV therapy. 1st ed. Advances in Anti-Viral Drugs; 2017 p. 1-43.

13. Kavya HR, Bhattacharyya S, Raghavendra Reddy HV. Analytical method validation of rizatriptan benzoate in fasted state simulated intestinal fluid using UV spectrophotometric method. Int J Pharm Res 2019;11(1):756-60.

14. Indian Pharmacopoeia. Controller of Publication, Govt. of India, Ministry of Health and Family Welfare, New Delhi; 2014.

15. Oldman AD, Smith LA, McQuay HJ, Moore RA. Pharmacological treatments for acute migraine: quantitative systematic review. Pain 2002;97(3):247-57.

16. Rizatriptan Dosage. Drugs.com; 2019.

17. Bhattacharyya S, Ray S, Gupta BK, Ghosh LK. Design, evaluation and statistical optimisation of a controlled release multiparticulate acyclovir delivery system. Lat Am J Pharm 2007;26(6):852-8.

18. Kamila MM, Mondal N, Ghosh LK, Gupta BK. Multiunit floating drug delivery system of rosiglitazone maleate: development, characterization, statistical optimization of drug release and in vivo evaluation. AAPS PharmSciTech 2009;10(3):887-99.

19. Lee Y, Conroy JA, Stepanavage ME, Mendel CM, Somers G, McLoughlin DA et al. Pharmacokinetics and tolerability of oral rizatriptan in healthy male and female volunteers. Br J Clin Pharmacol 1999;47(4):373-78.

20. Ozdemir N, Ordu S, Ozkan Y. Studies of floating dosage forms of furosemide: in vitro and in vivo evaluations of bilayer tablet formulations. Drug Dev Ind Pharm 2000;26(8):857-66.

21. Jethara SI, Patel MR. Development and evaluation of bilayer tablet of metoclopramide $\mathrm{HCl}$ and aceclofenac. Intel Prop Rights 2015;3(1):24-35.

22. Atram SC, Udavant YK, Salunke R, Neb GB, Shahi SR, Gulecha BS, et al. Formulation of bilayer tablet containing metoprolol succinate and amlodipine besylate as a model drug for antihypertensive therapy. J Pharm Res 2009;2(8):1335-47.

23. Patra C, Kumar A, Pandit H, Singh S, Devi M. Design and evaluation of sustained release bilayer tablets of propranolol hydrochloride. Acta Pharm 2007;57(4):479-89.

24. Marshall K, Lachman N, Liberman HA. The theory and practice of industrial pharmacy. 3rd ed. Mumbai: Varghese Publishing House; 1987.

25. The Indian Pharmacopoeia. The Controller of Publication, Govt. of India, New Delhi, 2018;3:A82-A85.

26. Sharif A, Rabbani ME, Akhtar MF, Akhtar B, Saleem M, Farzana K, et al. Design and evaluation of modified release bilayer tablets of flurbiprofen. Adv Clin Exp Med 2011;20: 343-9.

27. Parhi R, Bhupati SK, Suresh P, Kumar V. Formulation and evaluation of bilayer sustained release tablet of zolpidem tartrate. Indones J Pharm 2013;24(4):289-98.

28. Momin MM, Kane S, Abhang P. Formulation and evaluation of bilayer tablet for bimodal release of venlafaxine hydrochloride. Front Pharmacol 2015;6:144.

29. Nokhodchi A, Raja S, Patel P, Asare-Addo K. The role of oral controlled release matrix tablets in drug delivery systems. Bioimpacts 2012;2(4):175-87. 